\title{
Sistemas de Información Geográfica para la difusión web del patrimonio ambiental y cultural: el caso de la Ribera del Marco en Cáceres ${ }^{1}$
}

\author{
INTRODUCCIÓN: LA VALORIZACIÓN DEL PATRIMONIO CON TECNOLOGÍA SIG
}

En el área de la Ribera del Marco, situada en la ciudad de Cáceres - un espacio en declive social, económico y ambiental, pero con una gran riqueza paisajística y cultural- se ha diseñado un proyecto con Sistemas de Información Geográfica para la difusión de su patrimonio natural y cultural y que posibilite un impulso para su desarrollo socioeconómico y reduzca su abandono ${ }^{2}$.

La valorización del patrimonio cultural y natural y su exposición en los nuevos circuitos turísticos puede impulsar el desarrollo social y económico de espacios urbanos que en la actualidad están en crisis y con un continuo abandono de su población hacia zonas periféricas de la ciudad. Existen numerosas iniciativas y propuestas para la conservación y explotación de zonas monumentales y su entorno desde hace décadas, encaminadas todas estas iniciativas

\footnotetext{
${ }^{1}$ Agradecimientos a los proyectos "Turismap" financiado por Plan Nacional 2010 AVANZA$2 \mathrm{I}+\mathrm{D}+\mathrm{I}$, y al "Proyecto Ribera del Marco", a través de una subvención procedente del Mecanismo Financiero del Espacio Económico Europeo, formado por los países de Islandia, Liechtenstein y Noruega, con los cuales ha sido posible la realización de este trabajo.

2 "Puesta en valor de espacios degradados mediante TIG: el corredor de la Ribera del Marco (Cáceres)" ha sido un Proyecto financiado por el Ayuntamiento de Cáceres a través del Mecanismo Financiero del Espacio Económico Europeo gestionado por el Ayuntamiento de Cáceres y el Proyecto TURISMAP otorgado por el Plan Nacional 2010 AVANZA-2 I +D+I.
} 
a la correcta integración de patrimonio, nueva ciudad y los usos modernos del ocio y del turismo ${ }^{3}$ (Senabre, 2001).

La zona denominada Ribera del Marco presenta estas dos variantes, un patrimonio histórico y cultural valioso (uno de sus espacios es el Conjunto Histórico-Artístico de Cáceres declarado como Patrimonio de la Unesco en 1986, donde se localizan no solo excelentes muestras de arquitectura civil y religiosa de época renacentista, sino también signos de poblamiento prehistórico, romano y árabe, entre otras civilizaciones) y, también, una gran riqueza paisajística y ambiental, por localizarse en ella una zona de tránsito de la Ribera que conserva huertos tradicionales, antiguas fuentes y pozos, molinos, pontones, pasaderas, norias, acequias, etc.

La valorización de un recurso preexistente, vinculado al modelo de los itinerarios culturales como estrategia de identidad territorial para el desarrollo local, puede ser capaz de convertirse en una atracción de la inversión y una importante creación de empleo en estos espacios ${ }^{4}$. Diagnosticar estos recursos, su potencialidad de uso y desarrollo y que la sociedad perciba que a través de ellos puede satisfacer sus necesidades es una de las prioridades que se deben plantear en estudios como éste ${ }^{5}$.

La aparición de herramientas informáticas cada vez más potentes, la incorporación de Ambientes Virtuales, el constante avance en la denominada Visualización Geográfica o la introducción de modelos 3D 6 , han estado relacionadas directamente con nuevos proyectos de valorización de recursos turísticos desarrollados por parte de las administraciones públicas y entes privados. Estas aplicaciones han ido relacionadas con el planeamiento urbano para el conocimiento de las ciudades; estudios y simulaciones ambientales (contaminación, ruido, tráfico, desastres naturales, etc.); gestión en instalaciones comerciales y deportivas; diseño de redes de comunicación; usos temáticos y divulgativos en educación; etc.

Por eso, en este proyecto el planteamiento metodológico y su finalidad fue, desarrollar una cartografía de calidad y una serie de escenarios 3D que se puedan publicar en la web, y sirvan de escaparate para el potencial turista y el ciu-

\footnotetext{
3 Senabre, D. (2001): "Salamanca y su plan especial de protección: La efectividad en el cuidado del patrimonio". Estudios Geográficos, 62/244, pp. 525-542.

${ }^{4}$ Precedo, A.; Revilla, A. y Míguez, A. (2007): "El turismo cultural como factor estratégico de desarrollo: el Camino de Santiago". Estudios Geográficos, 68/262, pp. 205-233.

${ }^{5}$ Barrado, A. (2011): "Recursos territoriales y procesos geográficos: el ejemplo de los recursos turísticos". Estudios Geográficos, 72/ 270, pp. 35-58.

${ }^{6}$ Bosque Sendra, J. y Zamora Ludovic, H. (2002): "Visualización Geográfica y nuevas Cartografías", GeoFocus (Artículos), 2, pp. 61-77. ISSN: 1578-5157.
} 
dadano de Cáceres de la multitud de recursos endógenos que ofrece este espacio. El trabajo se ha desarrollado en cuatro fases: la creación de una cartografía ambiental, demográfica, económica, y social de la Ribera; una segunda fase con el estudio y la elaboración de una cartografía de la oferta y los recursos turísticos de la misma; una tercera donde se desarrolló una recreación en 3D de todo este espacio y una serie de videos de rutas turísticas diseñadas en la fase anterior y, por último, la unión de todos estos elementos en un geoportal web que supondría un primer contacto del usuario con el área de estudio y con el fin de potenciar turísticamente la zona ${ }^{7}$.

Se han diseñado rutas y paseos virtuales por la Ribera del Marco, para que el usuario pueda conocer este entorno o bien planificar una ruta antes de hacerla, indicando en ellas, los puntos de interés turísticos así como los distintos espacios de ocio de esta zona. Se ha querido plasmar toda aquella información ambiental, cultural y paisajística relevante, en cartografía de calidad que pueda ayudar al ciudadano en el conocimiento de todos los aspectos que engloban el contexto ambiental que supone la Ribera del Marco y su entorno cercano.

\section{METOdOlOGíA Y FUENTES: FASES DEL PROYECTO}

Para un óptimo conocimiento del Área de Estudio denominada Ribera del Marco y su posterior análisis, se elaboró una cartografía de calidad en formato Geodatabase con la delimitación de la Ribera del Marco y las 10 zonas que establecía el Proyecto Ribera del Marco. Se utilizaron como fuentes el Mapa Topográfico Nacional a escala 1:10.000, la Base Topográfica Nacional a escala 1:25.000 del IGN, la cartografía del proyecto Cartociudad y la cartografía de Distritos y Secciones del INE; y como imágenes raster las ortofotografías aéreas del Plan Nacional de Ortofotografía Área (PNOA) y los modelos digitales de elevaciones a escala 1:5.000 y 1:25.000 en formato raster del IGN. Se ajustaron todas estas fuentes al área de estudio, al mismo sistema de proyección (ETRS 1989 Huso 29 N) y en distintas capas relacionadas con la información que presenta. Para el análisis sociodemográfico, con las capas de los distritos y secciones censales del IGN y la cartografía de Cartociudad, se les agregaron los datos de los Censos y Padrones más actualizados (Padrón de 2013 y Censo del 2011) para poder introducir variables de población, estructura de vivien-

${ }^{7}$ Nieto, A.; Fernández, A. y García, C. (2012): "Puesta en valor de espacios degradados mediante TIG: el corredor de la Ribera del Marco (Cáceres)”, en J. Martínez, y P. Martín: Tecnologías de la Información Geográfica en el contexto del Cambio Global. Madrid, Ed. Instituto de Economía, Geografía y Demografía, Centro de Ciencias Humanas y Sociales, CSIC, pp. 371-383. 
das, nivel de estudios, procedencia, etc. Se obtuvieron mapas a nivel de secciones censales y con la representación visual de las capas de manzanas de la cartografía de Cartociudad (figura 1).

FIGURA 1

\section{CARTOGRAFÍA UTILIZADA PARA EL PROYECTO RIBERA DEL MARCO}

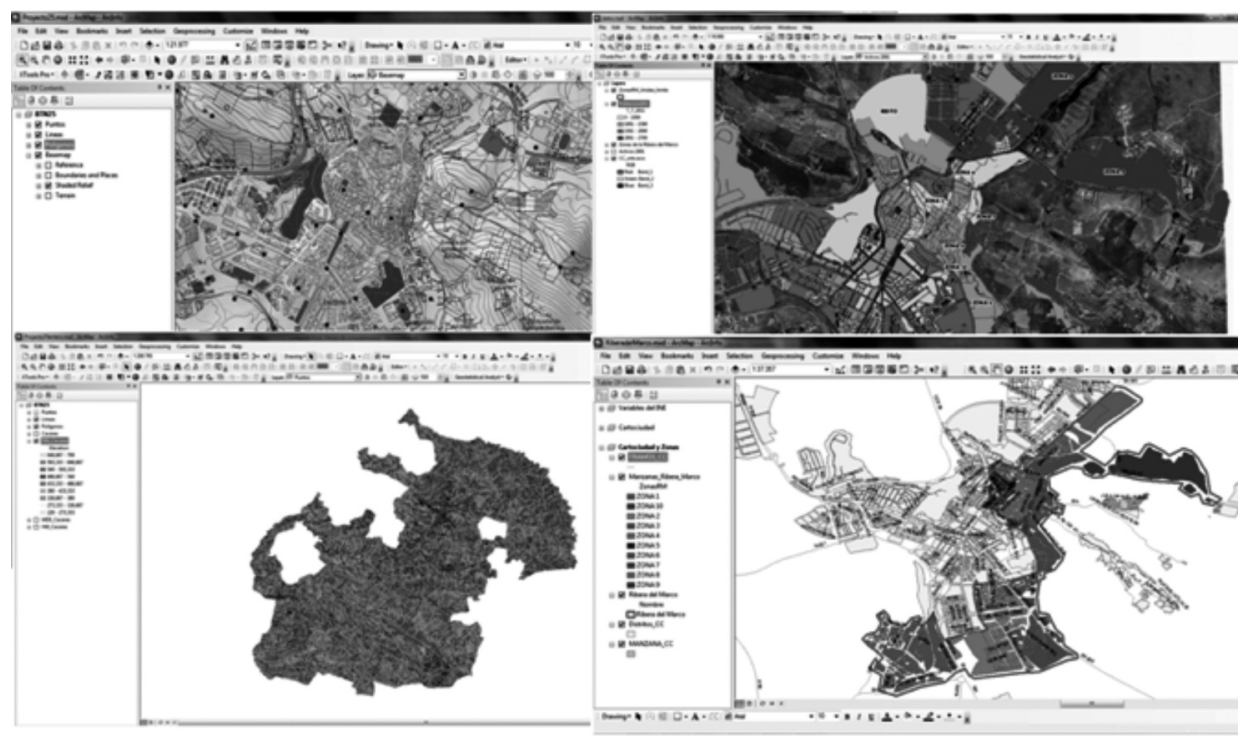

Fuente: Elaboración propia, Proyecto Cartociudad e IGN.

La segunda etapa de este proyecto, consistió en un estudio de los recursos y la oferta turística de la zona, y esta información se implementó en una cartografía, donde se introdujeron todos los puntos de información turística, elementos históricos, culturales y naturales de interés. Se utilizó la ortofoto del PNOA como base y se digitalizaron como capas en formato shape los Puntos de Turismo (donde se introdujeron recursos patrimoniales históricos como arcos, casas singulares, centros culturales, centros de interpretación, iglesias, monumentos y museos), Puntos de Interés (se añadieron recursos de gran riqueza paisajística y ambiental como fuentes, pozos, molinos, jardines, huertas, presas, molinos, ruinas y minas), Puntos destacables (con los 10 puntos más representativos de la Ribera), Rutas (con 9 recorridos turísticos para realizar por esta zona), Servicios (con la oferta de ocio y restauración) y otras capas de interés como parques, lagos, carreteras y zonas deportivas (figura 2). 
FIGURA 2

\section{CARTOGRAFÍA DE INFORMACIÓN TURÍSTICA DE LA RIBERA DEL MARCO}

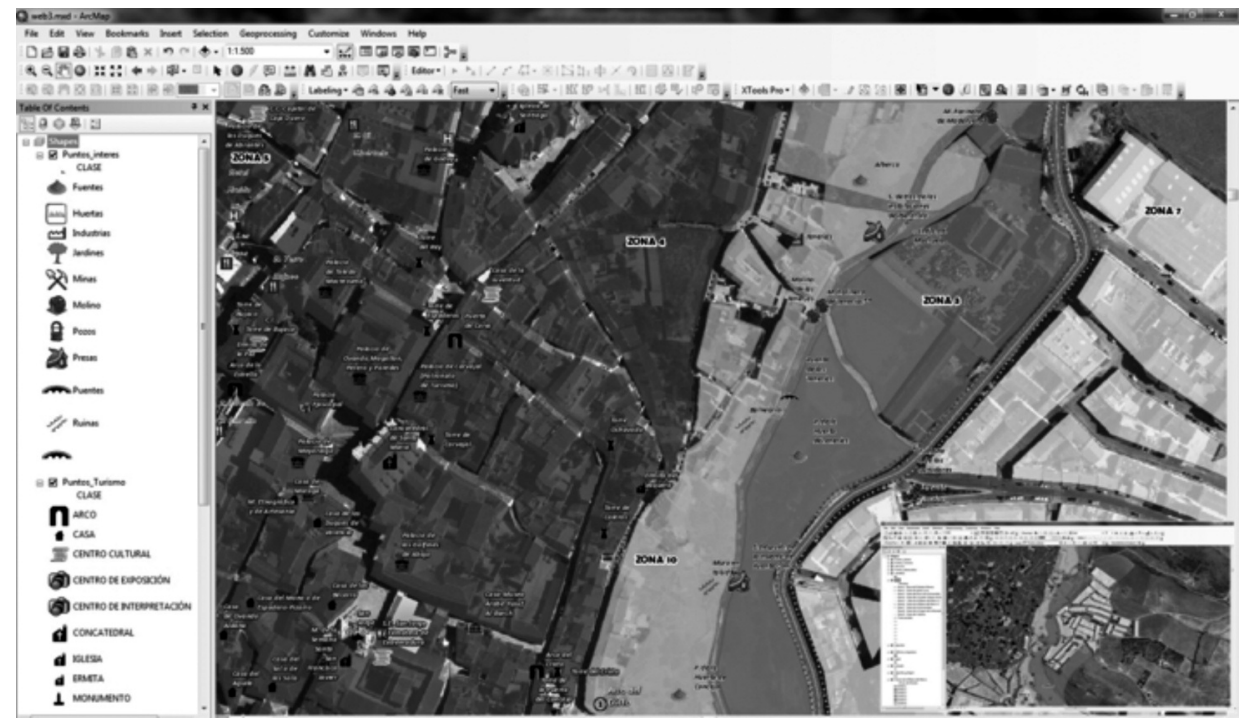

Fuente: Elaboración propia.

La siguiente fase del proyecto consistió en la creación de un escenario tridimensional y vuelos virtuales de la Ribera del Marco con las herramientas de Google SketchUp y el software ArcGis. Las ventajas de utilizar un software como Google SketchUp se encuentran en ser un programa de modelización bastante útil para la iniciación a los softwares de reconstrucción de modelos tridimensionales, por su rapidez y fácil manejo. Por otro lado, se decidió utilizar este software por su compatibilidad con otros SIG por permitir exportar estos escenarios en formatos KML/KMZ y ser visibles en programas como Google Earth o ArcGis. Los inconvenientes que nos encontramos al utilizar Google SketchUp fue el excesivo tamaño que ocupan sus modelos en 3D y para solventar esta dificultad, el espacio de trabajo lo subdividimos por pequeñas áreas que se unirán posteriormente al visualizarlas. El otro inconveniente vino dado porque el tiempo de trabajo para una correcta modelización fue extenso, debido a que la reconstrucción de los edificios tenía que ser modelizada de forma manual.

Como en toda modelización, hemos de tener siempre conocimiento sobre la geometría del edificio a reconstruir, por eso también la importancia del tra- 
bajo de campo y la obtención de fotografías digitales, para poder después introducir la diversidad de elementos urbanos. También, para dar un mayor realismo a la escena, se introdujeron elementos de la vegetación de la zona, como reconstrucciones de árboles y arbustos en la recreación de parques y avenidas arboladas.

Esta fase del proyecto obtuvo como resultado el levantamiento en 3D de los edificios y elementos urbanos (árboles, faroles, vallas, etc) que contienen las diez zonas en las que fue dividida la Ribera del Marco (figura 3).

FIGURA 3

CREACIÓN DE ESPACIOS TRIDIMENSIONALES CON GOOGLE SKETCHUP

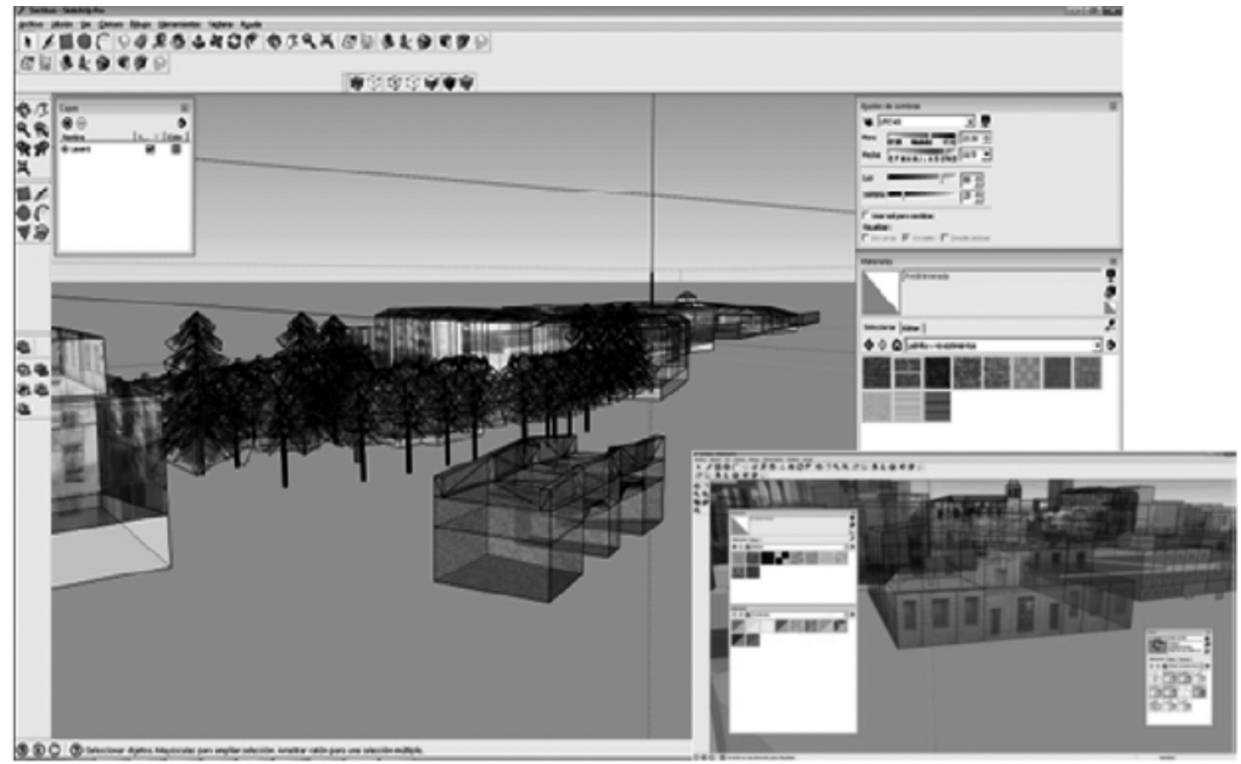

Fuente: Elaboración propia.

Se continuó con la creación de videos y por ello, se exportaron los modelos desarrollados en Google SketchUp (en formato SKP), a los formatos utilizados en los softwares ArcScene (COLLADA) y en Google Earth (KML). Se realizaron videos de las nueve rutas diseñadas en la Ribera del Marco y el Calerizo, que después introduciremos tanto en la página web del Proyecto como en Youtube (figura 4). 


\section{FIGURA 4}

\section{CREACIÓN DE VIDEOS O PASEOS VIRTUALES EN GOOGLE EARTH}

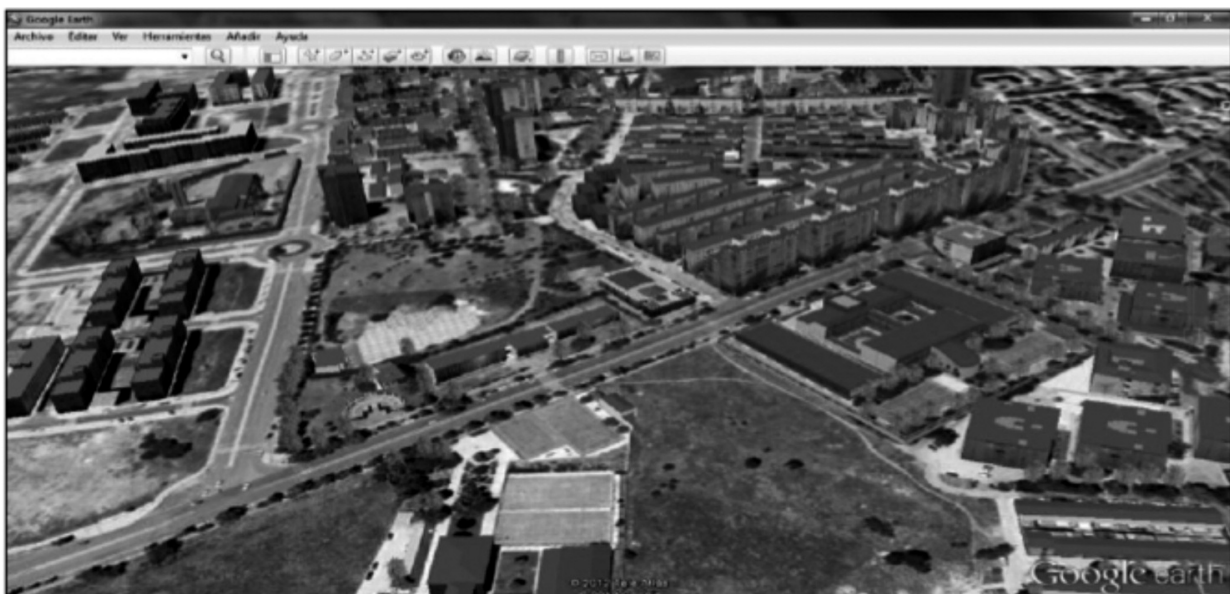

Fuente: Elaboración propia.

En la cuarta y última fase del proyecto, se elaboró un Portal Web donde se incluyeron la cartografía medioambiental, demográfica y socioeconómica; la cartografía de oferta y servicios turísticos, los espacios tridimensionales y los videos de las rutas para consulta de los posibles usuarios a través de Internet. La estructura del Portal Web se creó en Joomla, un sistema de gestión de contenidos que nos permite integrar, añadir o editar el contenido de un sitio web de manera sencilla mediante un código abierto programado mayoritariamente en PHP bajo una licencia GPL y la base de datos fue creada con un gestor MySQL así como de un servidor HTTP Apache.

La estructura principal del portal consta en su parte superior de un menú principal con distintas pestañas donde se puede acceder directamente a toda la información del proyecto (descripción de la Ribera, geoportal, videos, 3D y equipo de trabajo de este estudio). A continuación, dentro de esta página principal nos encontramos con un slide de imágenes seleccionadas de la Ribera del Marco, para que, desde el primer momento, el usuario conozca la belleza y singularidad de esta zona nada más acceder al portal. En la parte inferior nos encontramos también tres accesos directos a los principales recursos de la página web: el geoportal, los videos y la cartografía en 3D implementada en Google Earth (figura 5). Su página web es: http://imsturex.unex.es/ribera/ o a través de la web del Grupo de Investigación: http://imsturex.unex.es/sigrural. 
FIGURA 5

PORTAL WEB DE LA RIBERA DEL MARCO

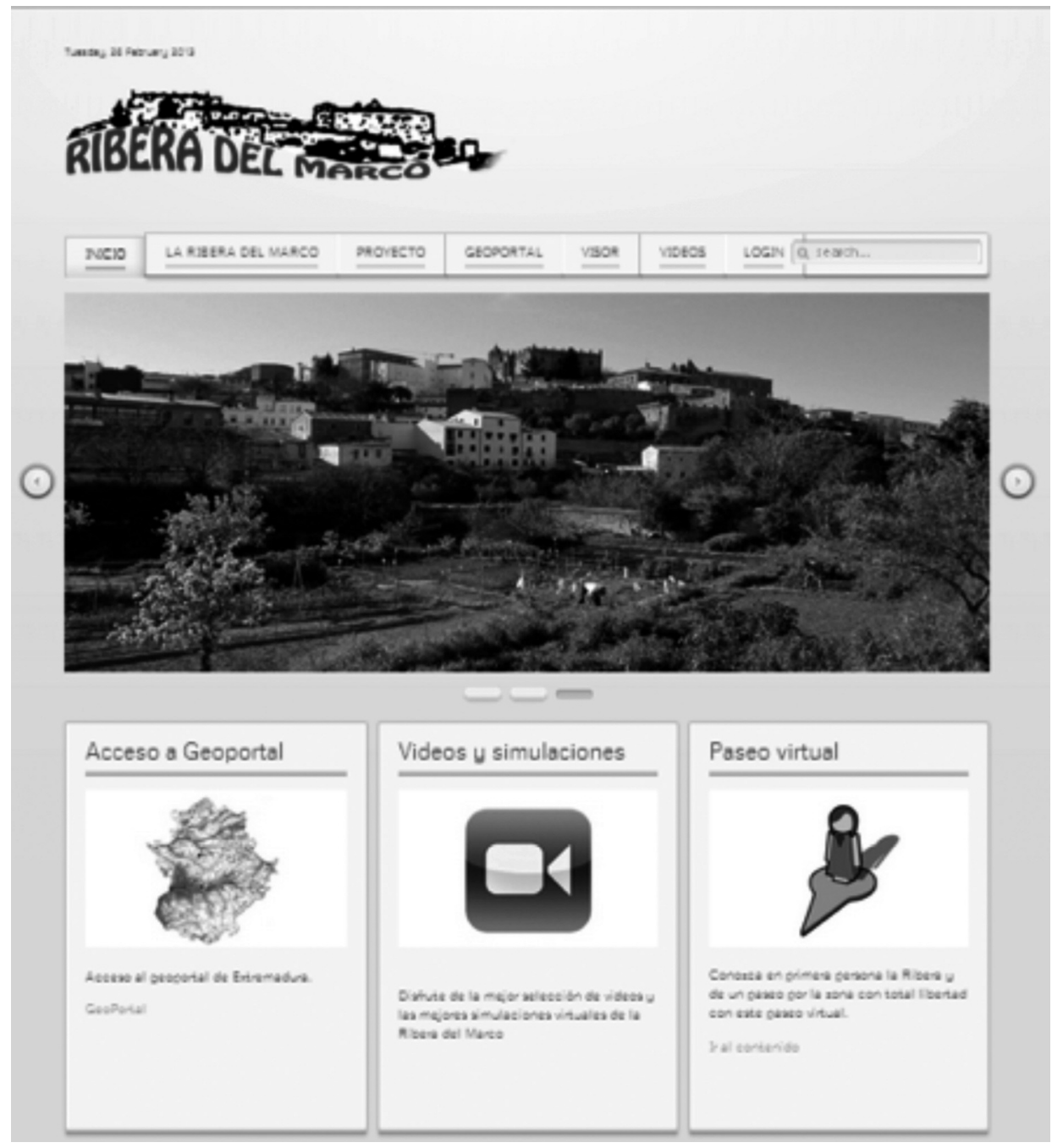

Fuente: Elaboración propia.

Estudios Geográficos, Vol. LXXVI, 279, pp. 739-750, julio-diciembre 2015 ISSN: 0014-1496, eISSN: 1988-8546 
En el Geoportal, se localizan las capas cartográficas de la Ribera del Marco y está diseñado como un visor cartográfico que pone a disposición todos los datos recogidos de las múltiples variables analizadas, tratadas y estandarizadas del territorio de la Ribera del Marco. Se introdujeron las variables medioambientales, demográficas, económicas y turísticas que se han creado en las fases uno y dos del proyecto. El visor cartográfico ha sido alojado como servidor web, para que todo aquel que lo desee pueda consultar sus bases de datos. Se ha utilizado ArcGis Server, un Geoportal que cuenta con numerosas herramientas de navegación, visualizado y representación de la cartografía, así como la posibilidad de realizar consultas a las bases de datos mediante sentencias de tipo SQL.

Se encuentran herramientas comunes a cualquier geoportal como la visualización y consulta de la información de todas las capas, la opción de imprimir los resultados, buscar localizaciones, medir distancias, dibujar rutas o ir directamente a puntos de interés y añadir cartografías básicas como imágenes de satélite, Open Street Map, imágenes con etiquetas, etc. (figura 6).

Además, se puede ir consultando la información de los registros que se añaden o se identifican en formato de tablas y gráficos con la descripción de los mismos. Como valor añadido se han diseñado dos script, para acceder directamente a las cartografías del Censo y del Padrón y poder realizar mapas de coropletas con las consultas de las distintas variables.

\section{FIGURA 6}

\section{GEOPORTAL CON LAS CAPAS DE LA RIBERA DEL MARCO}

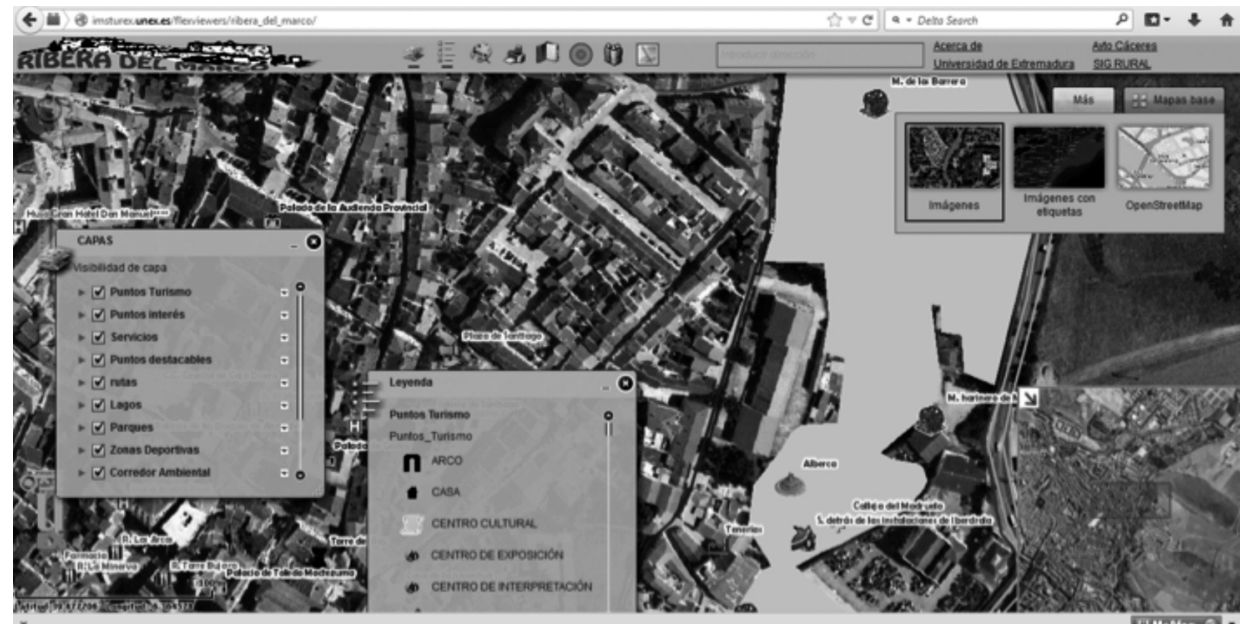

Fuente: Elaboración propia. 
El segundo acceso, el Paseo Virtual, fue creado con el complemento de Google Earth y su API de JavaScript donde nos permitió insertar Google Earth, un auténtico globo terráqueo digital en 3D, e incorporar los modelos en 3D creados en Google SketchUp de las 10 zonas de la Ribera (en formato KMZ) (figura 7). El usuario a través de su ordenador podrá moverse en primera persona por toda la zona de la Ribera, explorando los edificios más importantes y también podrá acceder mediante un click a información detallada de las zonas más importantes. Así, este paseo virtual se convierte en una forma sencilla de dar un paseo turístico por la Ribera del Marco sin salir de casa.

FIGURA 7

\section{ACCESO A LA CARTOGRAFÍA 3D DE LA RIBERA DEL MARCO Y GOOGLE EARTH}

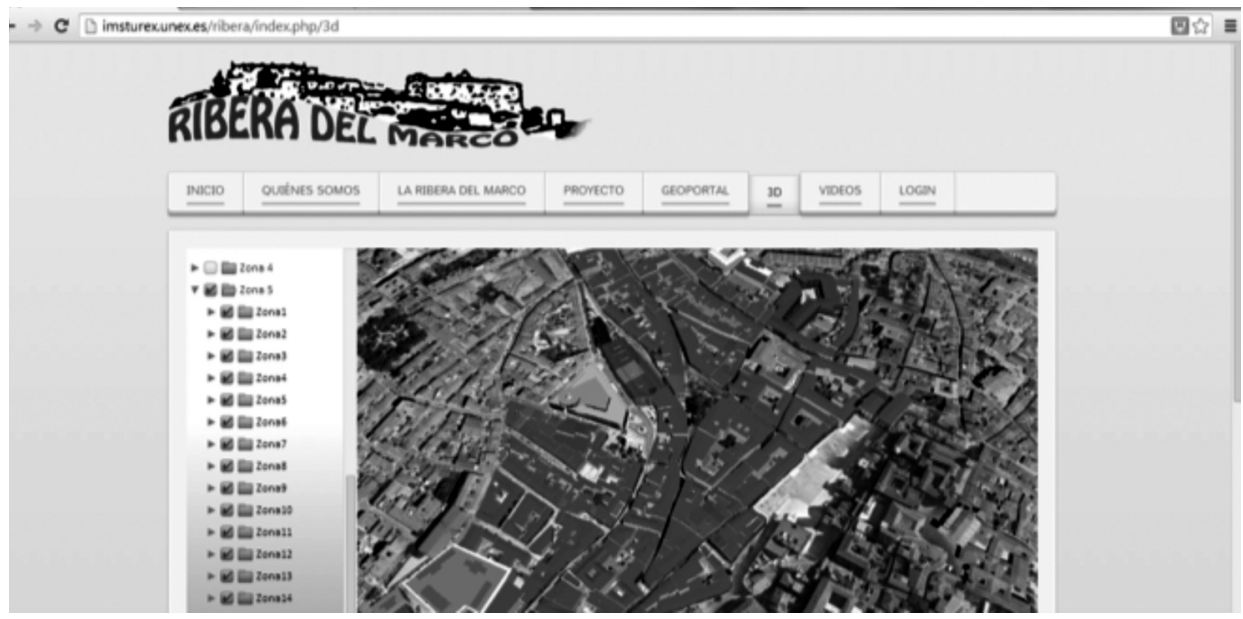

Fuente: Elaboración propia.

En el tercer acceso, videos y simulaciones, se pueden descargar videos de las 9 rutas diseñadas en el proyecto. Son videos realizados en Google Earth con los edificios y mobiliario urbano en 3D creados en Google Sketchup (figura 8 ). Se les ha añadido textos y audio, y, también pueden ser visualizados en Youtube. 


\section{FIGURA 8}

\section{PASEO VIRTUAL POR EL CASCO HISTÓRICO}

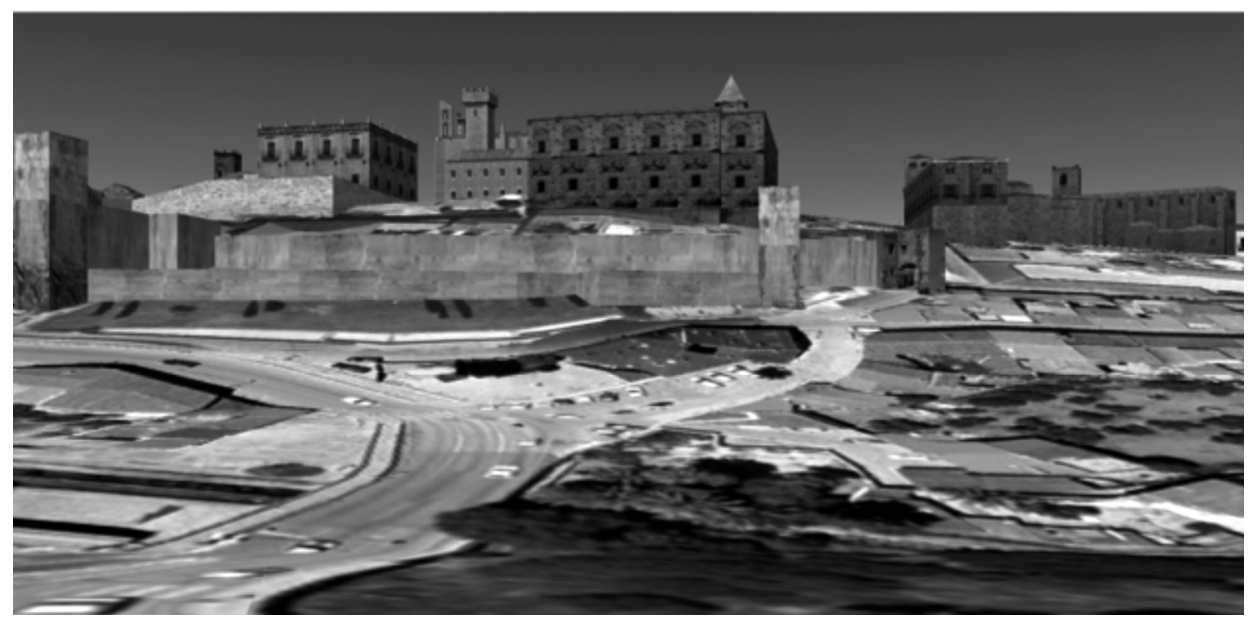

Fuente: Elaboración propia.

\section{RESULTADOS Y CONCLUSIONES}

En el desarrollo de este proyecto se han podido obtener los siguientes resultados. Ha permitido la difusión de nuestro trabajo en un portal web donde se ha puesto, para consulta del ciudadano, una cartografía ambiental, socioeconómica, demográfica y turística de calidad de la Ribera del Marco. Además, se han generado videos y paseos virtuales tridimensionales de la Ribera del Marco, mediante herramientas propias del modelado 3D, como Google SketchUp y otras propias del análisis geográfico como el software ArcGis y Google Earth. La introducción de datos geográficos de diversa procedencia (imágenes de satélite, fotografía aérea, GPS, LIDAR, modelos tridimensionales) y su visualización conjunta es un valor adicional que está proporcionando a la geografía y la cartografía formas más eficientes para el análisis de elevados conjuntos de datos espaciales, al aprovechar la enorme capacidad de integración de la mente humana a través de la vista ${ }^{8}$.

8 Ojeda Zújar, J. (2010): "Geovisualización: espacio, tiempo y territorio". Ciudad y territorio: Estudios territoriales, XLII/65-66, pp. 445460. 
Estas iniciativas intentan revitalizar el corredor, al potenciarla turísticamente, con la posible creación y regeneración de un tejido comercial y de servicios. Además, se acerca al ciudadano de una manera sencilla y entretenida el admirable valor natural, cultural y patrimonial que conserva la Ribera del Marco cacereña. Y se pretende la valorización de zonas como este espacio que se caracterizan por ser un área degradada, con serios problemas socioeconómicos y con un fuerte envejecimiento por la emigración de la población joven a los extrarradios de la ciudad de Cáceres, así como, la influencia de la actual crisis económica. Se intenta hacerla más atractiva a la población joven, partiendo de la instalación de nuevos servicios, empresas y comercios, que atraigan dicha población a estas áreas.

Se añade además la difusión de herramientas de la investigación espacial y la innovación en el ámbito geográfico que están en constante evolución, aunque en futuros estudios se pretenden mejorar y perfeccionar los resultados con el avance de las mismas.

Ana Nieto Masot

Universidad de Extremadura 